\title{
Minimum Harmonic Distortion Losses and Power Quality Improvement of Grid Integration Photovoltaic- Wind Based Smart Grid Utilizing MOPSO
}

\author{
Adel Elgammal and Tagore Ramlal
}

\section{ABSTRACT}

Increased usage of combined PV-Wind renewable energy sources is seen as a positive step toward reducing air pollution and carbon emissions. However, since non-linear loads have increased dramatically, voltage quality and harmonic distortion concerns have arisen, affecting the operation of combined PV-Wind RES and smart-grid electrical transmission structures. This study shows how a Shunt active power filter may improve energy quality in a microgrid structure at the distribution level. The major goal of this article is to find an appropriate controller approach for improving the shunt active power filter's compensating capacity. This paper simulates a PV-Wind hybrid renewable energy system that operates in the presence of unpredictably variable solar and wind energy resources. The objective is to allow the construction of an electrical control structure that produces the right duty cycle. It will aid in the regulation and stabilization of voltages at dc/dc energy conversion plant. Simulation is used to assess the proposed control system's ability to enhance power quality. The device's compensating capability is mostly determined by the DC link capacitor voltage control. The closed loop functioning of a proportional integral controller is used to attain this voltage regulation in the past. To increase the functioning of a shunt active power filter, the MOPSO procedure approach has been presented. The performance of suggested approaches and the comparison of different pulse generating strategies have been validated in the SIMULINK/MATLAB model environment. The suggested technology successfully improves power quality on the grid and maintains a steady voltage on the grid despite variations in RE output and load.

Keywords: Ac/dc conversion, Power Quality, Smart grid, Harmonic Distortion, integrated PV-Wind.

\section{INTRODUCTION}

Synchronization, system stability, and Power quality issues have all been exacerbated by the incorporation of large level solar and wind farms into a transmission structure [1]. Because of the fluctuating wind ow/sunlight and fluctuations in the energy load, these RE facilities were linked to the transmission structure, posing significant harmonic distortion and voltage quality issues [2], [3]. When the static switch is turned on, each DG unit uses the microgrid's frequency and voltage to regulate reactive and active power. The DG unit should be attached to the central utility grid when in gridlinked mode. Under addition, each DG unit's actual and reactive power may be controlled in this mode of operation [4]. The connecting of an microgrid to the central grid structure is the critical region to examine the energy quality issues that influence voltages of utility grid, such as voltage sags, harmonics, high reactive power, and unbalanced loads on the power system network's overall performance. Because voltage quality problems in power system networks are not a new concept, modification methodology in power quality has grown in recent years [5], [6]. Recent advancements in MG have encouraged many additional stability concepts via converters and inverters, reducing power instability. To guide the voltage and frequency of the Distributed generator units, controllers will be utilised to track the current components in the control loop of the Distributed generator units [7]. In the presence of voltage and frequency, a combination of optimization approach and controller design and techniques is useful for reducing disturbance. Droop controllers could consider coordinating several DG in a micro grid system. It determines how much energy sharing is needed to keep the frequency and voltage of the micro grid stable [8]. Interfaced inverter DG can be used in the power structure to reduce voltage and frequency instability and increase power stability. The caveat of their classifications taking into consideration effective stabilisation has been critical with the different recent breakthroughs of modern controller approaches [9]. In comparison to other micro grid systems, PV solar systems with grid linked inverters are more cost effective and require less maintenance. This sort of micro grid can have either DC or AC power flow. To decrease the amount of power electronic converters to decrease recharge time, a DC grid for direct current type loads for example 
hybrid and electric car charging station is needed [10]. Because there is no synchronisation issue and no reactive power flow on a direct current micro grid, no phase correction in energy flow is required [11], [12]. When wind and solar energy generating resources are disrupted, direct current storage devices can be linked to the MG as a better way to sustain electricity flow. Power electronics converters can also connect energy generating resources to the micro grid efficiently. The solar farm requires DC-DC converters, while the wind farm requires AC-DC converters. Electrical energy control methods can be used to keep the grid voltage stable [13]. At charging stations, Direct current loads, like as vehicle batteries, can be linked to micro grid. Maintaining voltages near to the reference value is critical in the micro grid transmission line; otherwise, the system may become unstable [14], [15]. The addition of electricity from fuel generators, solar/wind energy, and battery banks may cause significant harm to the equipment, network, and ultimately the financial system [16]. Stability measurements can tell us if a system is stable or on the approach of becoming so. They should be assessed at each grid point in order to take the appropriate action [17]. The voltage and current harmonics will be the two forms of harmonics that will be alleviated in the distribution system. Current harmonic is determined at the cables and lines, whereas voltage harmonic is measured at the bus. A passive filter is the most frequent component used to eliminate these harmonics. Harmonic currents can be prevented from entering into systems by using passive filters that offer a low-impedance route for them. Passive filters have been utilized in a number of studies to reduce harmonics in power systems, with single tuned filter being the most common [18]-[22]. Single tuned filter is meant to minimize or remove single frequency from the network based on the design inductance, capacitance, and resistance values [23]. [24] Proposes a hosting capacity assessment for a distribution structure that has been deformed due to a PV connection. A passive filter is utilised to boost harmonic-constrained hosting capacity, improving harmonic filtering, power factor, and voltage. A harmonic voltage compensator and asymmetric Synchronous Reference Frame Control system with a static VAR compensator linked to the grid to attenuate the harmonic has been proposed [25], where the HVC was used to minimize voltage THD. Despite the fact that many researchers have utilised passive filters to reduce harmonics, only a few have addressed both current and voltage harmonics in their analyses, particularly for CS. The generation of energy from solar and wind plants has been fundamentally raised due to its reciprocal accessible nature throughout the day. The availability of wind speed and sunlight-based lighting will determine when it is appropriate to regulate output [26]. Due to significant environmental effect of sustainable energy sources, the electricity generated from them results in irregular and discontinuous voltage. The electricity generated by solar energy systems is a vital source of sustainable energy that emits almost no ozone-depleting substances and does not consume any non-renewable energy sources [27]. Matrix linked sustainable power source assets, for the most part, have space needs as they are connected to the structure via lengthy transmission networks distant from load centres [28]. Work on the PV system supports the 3 stage inverter linked to the system for a smooth prolonged operation and for the most reliable electric power structure. The power supplied by converters, notably, three stage inverter with dc-dc converter, may now be used and stepped up to the grid, owing to the progress and enhancement of intensity devices. The power sources are integrated to define the sustainable energy system, which smooths out these progressions. To seek the most remarkable power sources, MPPT control calculation is necessary [29]. Many studies used MPPT calculations including artificial neural networks, hybrid systems, fuzzy controllers, perturb and observe, and hill-climbing to isolate highest energy from cost-effective sustainable energy resources [30]. The first phase of the plan assists with PV output voltage, while the second step turns this direct current management into excellent airpower cooling [31], [32].

This article presents an analysis of voltage stability and THD for the regular coupling of a structure linked solar system. The harmonic current reduction control plot is one approach presented in this study for the network connected with photovoltaic structures. The voltage alteration that arises at junction point of a linked grid is likewise controlled by this harmonic current reduction technique. Furthermore, it enhances the grid's power quality and lowers THD. This research looks at an isolated micro grid to see how inrush, transient currents, and other grid disturbances affect power quality. Grid systems and power-generating units may be harmed as a result. To reduce the impact of external factors, this research looks at transient transmission and voltage spikes. Internal factors like frequency, inductance, and capacitance control of IGBT switches, as well as external variables like sunlight/wind flow, create instability. As part of the smart grid, a power and voltage conversion closed-loop control structure are being created, and its capacity to manage large-scale power flow is being investigated. By employing a controlled duty cycle to energy conversion unit, the control structure prevents voltage drop. The grid's power flow is maintained during energy shortages. It is controlled by gaining electricity from batteries during off-peak hours and then recharging them. To evaluate environmental impacts on electric power production, Simulink/MATLAB simulations are used to examine the system. The simulation findings were evaluated with a mathematical investigation to identify the impacts of overloading and under loading in the micro grid.

\section{PRoposed SYSTEM}

Every day, more solar and wind and farms are being built. However, in the meanwhile, transmission networks are becoming overburdened, reducing their efficiency. Environmental variables and load changes must be studied in order to carry out RE transmission on a transmission system. Because environmental and load settings are always changing, it's impossible to predict what will happen next. As a result, maintaining consistent stability for renewable energy transmission is extremely difficult. Overloading, synchronisation, and Environmental conditions are the major causes of renewable energy transmission instabilities. The network's efficiency is also harmed as an outcome of overloading and other sorts of fluctuations. There is a need for a new form of system that can transfer electricity efficiently while taking into account the restrictions posed by 
renewable energy sources. The electricity network is designed to deal with instability concerns by ensuring sustainability at each point in the system (due to changing load fluctuations and climatic conditions within the system). Instability has the potential to cause significant harm to the equipment, network, and, ultimately, the economy. For renewable energy transmission, smart micro grid architecture is still a pipe dream. As a result, research into the smart micro grid is required in order to address power flow issues. The power sector benefits from the micro grid since generated energy is routed through it rather than through the distribution grid. This article suggests an innovative paradigm for transferring renewable energy, with the goal of increasing renewable energy efficiency while minimising power flow difficulties on power grid. It linked electric automobiles directly to micro grid, which allows them to receive and transmit electricity. Closed loop control techniques must be used to provide automated power flow regulation and stability. In a MATLAB/Simulink environment, the suggested smart grid model structure (illustrated in Fig. 1) is simulated. A measuring structure, stability control structure, smart protection system, and monitoring and control centre to manage electric flow on a micro grid are all included. The smart micro grid transmission structure connects energy resources (energy storing systems and fuel, solar, wind generators) to loads (EV charging station). To transport electricity with high dependability, the smart grid employs communications, computer technology, protection, and control. To enhance the dependability of electricity usage such as power efficiency and voltage control, the smart grid includes renewable energy generating and storage alternatives. The energy storing system is among the most significant components of the smart grid. To efficiently transmit RE into the grid, you'll need an energy storage system that can store a lot of energy during peak periods and charge up during off-peak hours. Due to DC power transmission, a direct current micro grid comprises solely of in series resistances throughout the length of a line, with inductance and capacitance being ignored. Power fluctuates constantly on a direct current grid fed by solar and wind energy producing units. If the load is inductive or capacitive, the grid will experience transients and spikes, necessitating the need of a regulating mechanism to restore balance. The duration of current ow determines the desired voltage, with the inductor performing better at low-level frequency and the capacitor performing better at high-level frequency. To manage the frequency and stabilise the voltage of IGBT switches, an energy conversion structure comprising DC/DC and $\mathrm{AC} / \mathrm{DC}$ components is employed. It detects current and voltage, and then applies the appropriate duty cycle to IGBT switches to control the voltage ow at micro grid. Boost converters are utilized to increase voltage whereas Buck converters are utilized to reduce voltage from solar panels. At the micro grid monitoring and control centre, buck-boost converters are utilised to regulate voltage. The microgrid's control structure is used to manage voltage flow in an AC/DC energy conversion structure. The feedback controller is implemented using a MATLAB script to determine the right duty cycle. To get the appropriate voltage, the controller functions similarly to the microcontroller in that it applies varied pulses to regulate the IGBT converter switches frequency. To prevent instability, the controller gathers 2 sensor signals from an output converter. To compute the correct output and produce error signals, the controller compares these signals to a set of reference signals. Highpower insulated gate bipolar transistor switches have extremely low switching frequencies, resulting in voltage fluctuations. A PWM control method is utilized to eliminate harmonics and the output waveforms are smoothed in order to overcome this problem. By applying the eight $\mathrm{ON}$ and OFF states of the three phase Pulse Width Modulation pulses, PWM switching controls the output voltage of the power converters. Between 0 to 1 is the duty cycle given to power converter switches. The duty cycle at a converter station regulates the speed of the IGBT switches. Voltage spikes appear to be decreased when the PWM pulse frequency is increased. Power electronic filters are used to evaluate and minimise transients and voltage spike waveforms. The voltage on the DC micro grid is regulated by delivering the required energy to the load and applying the proper duty cycle at the $\mathrm{AC} / \mathrm{DC}$ insulated gate bipolar transistor converter switches. To produce the exact duty cycle, a closed loop feedback system is utilised. Through closed feedback connections, the controller receives the signal from the converter's output. By comparing the output feedback voltage to the reference voltage, it generates the variable duty cycle. To update the duty cycle, it detects the voltage difference between reference and output voltage. The controlled voltage is then sent to the electric car charging station through a smart grid.

The variable filter will be placed and sized depending on 5 parameters: apparent power losses, maximum THDV, maximum THDi, THDi summation, average THDi, , , and for the whole system. The 3 THDi-related indicators are utilised to ensure that THDi is within reasonable bounds on all buses. The following fitness functions will be assessed to attain best feasible result. The basic formulae for calculating THD of current and voltage are as follows:

$$
\begin{aligned}
& \min f_{1}=T H D_{v}=\frac{\sqrt{\sum_{h=2}^{9} V_{h}^{2}}}{V_{1}} \times 100 \% \\
& \min f_{2}=T H D_{i}=\frac{\sqrt{\sum_{h=2}^{9} I_{h}^{2}}}{I_{1}} \times 100 \%
\end{aligned}
$$

An m bus system's overall power losses comprising of harmonic frequencies losses are:

$$
P_{\text {Loss }}=\sum_{h=1}^{9}\left(\sum_{i=1}^{m} P_{\text {Loss }, i}\right)
$$

The problem's objective function is to minimise energy loss during a twenty four hour duration:

$$
\min f_{3}=\text { Energy Loss }=\sum_{t=0}^{T} P_{\text {Loss }} \times \Delta t
$$

$\Delta \mathrm{t}$ is the time interval, and $\mathrm{P}_{\text {loss }}$ is total power loss at $\mathrm{t}$ hour. (normally taken as 1 hour). 


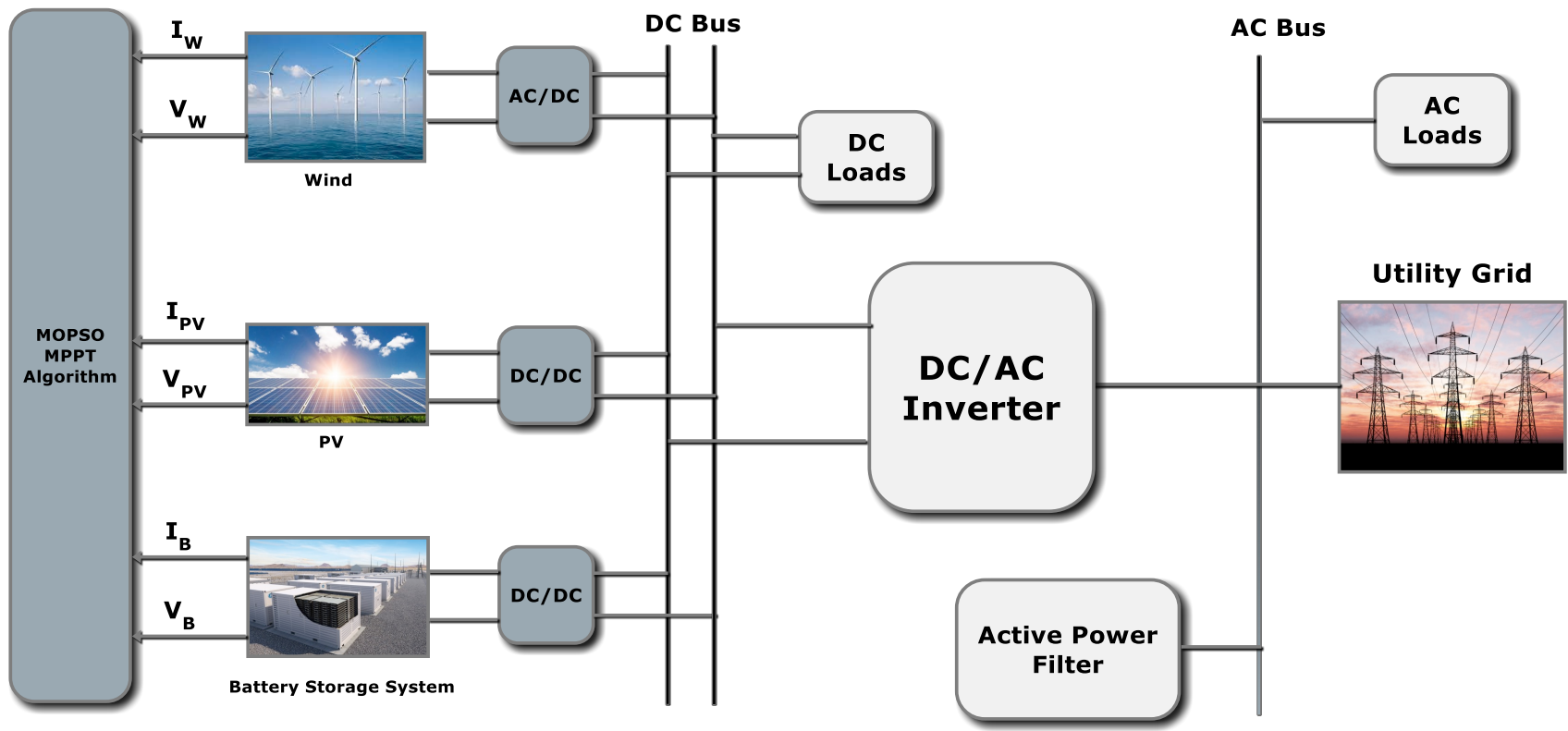

Fig. 1. An illustration of the integrated smart model, which includes storage system, photovoltaic system, the wind turbine and micro grid components.

\section{Simulation Results}

To investigate how to improve power quality on the micro grid, researchers employed SIMULINK/MATLAB simulations and its power components models. Regardless of solar/wind energy variations, the needed electricity is always accessible on the micro grid. It displays the system's ability to provide the necessary power to non-linear needs throughout a 24-hour period. Because of the micro grid's limited power flow and short operation durations, losses are minimal. There is a surge in power flow, and the electric flow on the grid is constant, regardless of fluctuations in solar/wind power. It has been confirmed that the suggested control algorithm works as intended. It improves system efficiency by decreasing losses and extracting the most power from wind/solar energy resources. To regulate voltage, the controller monitors the current and voltage input and generates duty cycles. The Simulink/Matlab platform was utilized to check the implementation of a SAPF for microgrid structures in order to address current-related energy quality issues. Microgrid sources are regarded to be an excellent source for study in this case. The functioning of filters has been examined in this article for two distinct controller circuits, namely the PI controller and the MOPSO controller. Simulation results show a comparison of direct current linked voltage by proportional integteral and MOPSO controllers. The tracking of the real direct current linked voltage with the specified reference voltage demonstrates the filter's performance. Both the traditional and suggested controllers keep the dc link voltage constant. However, a performance comparison has been conducted here for both techniques. The disturbance in the microgrid system, although the dc link voltage is regulated in both approaches. When compared to the MOPSO algorithm approach, the PI controller has a significant peak overshoot. Peak overshoot in the PI controller is $37.5 \%$, whereas in the MOPSO, it is $2.25 \%$. MOPSO also has a faster settling time than the PI controller, which is 0.25 seconds against 0.65 seconds for the PI controller. The performance of MOPSO is clearly superior to that of the PI controller based on the analysis.
Energy variations in a capacitance and inductance in line/converters and on load side produce oscillations. Varied inductors have different load responses, as has been seen. Lower peak currents are produced by higher inductance, which decreases losses and increases efficiency. Second, the current ow on the micro grid is affected by the switching frequency of the insulated gate bipolar transistor switches. Lower current ripples are caused by higher switching frequency, and vice versa. A shunt active filter is used to eliminate harmonics and transients from the micro grid transmission structure. It maintains the current level and regulates the voltage by minimising voltage spikes. Between the battery bank and the DC micro grid is a bidirectional converter with control. It monitors the electric flow at the grid to charge and discharge the batteries. To measure the energy flow, sensors are linked to every segment of the micro grid. To protect it against short circuits and other issues, the grid is safeguarded with circuit breakers. The suggested shunt active filter is utilised to minimise PWM pulse-induced ripples in the energy supply. The output current and voltage of the converter system are affected by variations in inductance and capacitance. The output capacitors are a vital feature of a feedback converter structure since they are a crucial component in reducing the power supply's transient response Input voltage variations are directly influenced by the load current. Transients in the input voltage are caused by an increase in transients at the output current. Lower input voltage allows for larger current flow, which increases transients; therefore, a greater input capacitance is necessary to reduce voltage transients. To lower the voltage, and enable the flow of energy, the converter's output capacitors must be charged and discharged. Increase the switching frequency and Increase the capacitor values of the converters to decrease transients. The controller monitors variations in output voltage and adjusts the duty cycle to compensate when a transient happens. Even if the duty cycle is increased to $100 \%$, the output filters inductance limits the change in current output. The objective of control algorithm is to maintain energy flow under quickly altering environmental conditions for example wind speeds and irradiance. To do 
this, the energy converter switches are given the appropriate variable duty cycle. The power factor analysis before and after the filter is connected was studied. The current and voltage waveforms are not in phase without the filter, resultant in power factor of 0.70483 before the microgrid system's compensator is attached, according to the findings. The power factor has been increased to 0.999. Using the provided technique, the current and voltage are observed to be in phase with each other. This method improves the power factor of the SAPF, ensuring its performance.

Tables I-V compare the THD percent of current and voltage on DC and AC buses using PI, SOPSO, and MOPSO controller techniques. The THD percent for current without filter is observed to be $44.71 \%$. Without a filter, the percent THD for current utilising PI control is 41.16, but with a filter, it is 4.69. It appears to be 2.014 using adaptive MOPSO. THD is reduced by $93.07 \%$ when the suggested MOPSO algorithm is used for a shunt active power filter. This research illustrates the effectiveness of the proposed MOPSO algorithm for dynamic non-linear load variation. When compared to a PI controller, MOPSO has a lower percent THD of current. Because the percent THD number is less than 5\%, the IEEE standard of percent THD limitation has been met. After SOPSO finds the best settings for the shunt active filter, the maximum THDV is reduced from $1.5104 \%$ to $0.8423 \%$, and the maximum THDi is reduced from $3.0457 \%$ to $1.2457 \%$. However, the network's overall apparent losses have grown. As a result, in the next stage, a MOPSO method is employed to address this issue. The MOPSO results are a collection of set solutions, with the finest solution being the finest provided that one of their objective tasks is dominant over the others. The best solution from the Pareto set is then selected. The answer in this article is made up of THDV, THDi and power loss.

TABLE I: \% THD FOR AC BUS VOLTAGE

\begin{tabular}{|c|c|c|c|c|c|c|c|}
\hline \multirow{3}{*}{ PHASES } & \multicolumn{7}{|c|}{ \% THD FOR AC BUS VOLTAGE } \\
\hline & \multirow{2}{*}{$\begin{array}{c}\text { EXISTING \% } \\
\text { THDACV }\end{array}$} & \multicolumn{2}{|c|}{ PI CONTROLLER } & \multicolumn{2}{|c|}{ SOPSO } & \multicolumn{2}{|c|}{ MOPSO } \\
\hline & & $\%$ THDACV & \% REDUCTION & $\%$ THDACV & \% REDUCTION & $\%$ THDACV & $\%$ REDUCTION \\
\hline PHASE A & 37.8945 & 4.2135 & 89.12 & 3.0124 & 92.92 & 2.0165 & 93.41 \\
\hline Phase B & 36.7845 & 4.0132 & 89.92 & 3.1024 & 92.01 & 2.1460 & 93.07 \\
\hline PHASE C & 37.2541 & 4.7081 & 88.98 & 3.4016 & 91.84 & 2.0365 & 93.85 \\
\hline
\end{tabular}

TABLE II: \% THD FOR AC BUS CURRENT

\begin{tabular}{cccccccc}
\hline \hline & \multicolumn{7}{c}{ TABLE II: \% THD FOR AC BUS CURRENT } \\
\cline { 2 - 7 } PHASES & EXISTING \% & \multicolumn{2}{c}{ \% THD FOR AC BUS CURRENT } \\
\cline { 2 - 7 } & THDACC & \% THDACC & \% REDUCTION & \% THDACC & \% REDUCTION & \% THDACC & \% REDUCTION \\
\hline PHASE A & 44.58 & 5.14 & 90.74 & 4.84 & 93.89 & 3.02 & 95.23 \\
PHASE B & 45.32 & 5.02 & 90.25 & 4.21 & 93.47 & 3.14 \\
PHASE C & 45.89 & 5.45 & 90.85 & 4.65 & 93.84 & 3.07 \\
\hline \hline
\end{tabular}

TABLE III: \% THD FOR DC BUS VOLTAGE

\begin{tabular}{|c|c|c|c|c|c|c|}
\hline \multicolumn{7}{|c|}{ \% THD FOR DC BUS VOLTAGE } \\
\hline \multirow{2}{*}{ EXISTING \% THDDCV } & \multicolumn{2}{|c|}{ PI CONTROLLER } & \multicolumn{2}{|c|}{ SOPSO } & \multicolumn{2}{|c|}{ MOPSO } \\
\hline & $\%$ THDDCV & \% REDUCTION & $\%$ THDDCV & \% REDUCTION & $\%$ THDDCV & \% REDUCTION \\
\hline 38.49 & 4.14 & 90.17 & 3.025 & 94.25 & 2.28 & 95.23 \\
\hline
\end{tabular}

TABLE IV: \% THD FOR DC BUS CURRENT

\begin{tabular}{ccccccc}
\hline \hline & \multicolumn{5}{c}{ \% THD FOR DC BUS CURRENT } \\
\hline \multirow{2}{*}{ EXISTING \% THDDCC } & \multicolumn{2}{c}{ PI CONTROLLER } & \multicolumn{3}{c}{ SOPSO } & MOPSO \\
\cline { 2 - 7 } & \% THDDCC & \% REDUCTION & \% THDDCC & \% REDUCTION & \% THDDCC & \% REDUCTION \\
\hline 47.23 & 6.49 & 88.25 & 5.49 & 92.58 & 4.21 & 93.2 \\
\hline
\end{tabular}

\begin{tabular}{|c|c|c|c|c|}
\hline FUNCTION & EXISTING & PI CONTROLLER & SOPSO & MOPSO \\
\hline MAX THDACV & 1.3654 & 0.9124 & 0.7564 & 0.6487 \\
\hline MAX THDDCV & 1.4265 & 0.9943 & 0.8246 & 0.7132 \\
\hline MAX THDACC & 2.0146 & 1.0132 & 0.9019 & 0.8479 \\
\hline MAX THDDCC & 2.1369 & 1.0324 & 0.9214 & 0.8147 \\
\hline AVERAGE THDACV & 0.7256 & 0.5589 & 0.4785 & 0.3165 \\
\hline AVERAGE THDDCV & 0.7745 & 0.6278 & 0.5214 & 0.4019 \\
\hline AVERAGE THDACC & 0.8624 & 0.6624 & 0.5512 & 0.4197 \\
\hline AVERAGE THDDCC & 0.8821 & 0.6471 & 0.5074 & 0.4496 \\
\hline SUM THDACV & 14.9514 & 12.0354 & 9.0279 & 8.9856 \\
\hline SUM THDDCV & 15.7832 & 13.0764 & 9.9132 & 8.1278 \\
\hline SUM THDACC & 17.6598 & 13.2879 & 10.0236 & 9.9845 \\
\hline SUM THDDCC & 16.8514 & 12.0365 & 10.2654 & 9.5647 \\
\hline SLOSS & 0.05746 & 0.05432 & 0.04584 & 0.40943 \\
\hline
\end{tabular}

\section{CONCLUSION}

A smart power filter concept is proposed for a grid independent from the national distribution system that connects variable RES such as solar and wind to non-linear demands. The purpose is to eliminate power quality concerns from the current transmission system, such as harmonics, voltage drops, transients, and losses. Energy storage devices are included in the smart grid to provide electricity to the grid during times of high demand or when renewable energy sources are insufficient. The grid's voltage is controlled by monitoring power flow at various locations. It's also adjusted by putting in place a smart communication structure that sends feedback signals to the control structure. The validity 
of Shunt APF for microgrid applications is investigated in this study. The filter's performance was tested using the Simulink/Matlab platform. According on the results of simulation research of the proposed MOPSO controller technique and the standard proportional integral controller, the recommended MOPSO approach technology provides rather good performance. The utility supply current as well as, direct current linked capacitor voltage regulation waveform both becomes sinusoidal with supply voltage. As a consequence, the shunt APF proposed in this work for nonlinear load microgrid application was successful. The suggested MOPSO method enhanced the filter's compensating capacity. As a result, the filter is shown to be successful in meeting IEEE harmonic limits recommendations. A grid linked microgrid structure's power quality was enhanced by means of the MOPSO algorithm centred SAPF. The control system at the buck converter station provides the proper duty cycle. Based on the results of mathematical simulation and modelling, filters are employed to eliminate power fluctuations. To evaluate the suggested micro grid's voltage control capabilities, it is mathematically analysed and simulated using common Simulink toolboxes over a 24 hour period. The simulation results show a $99 \%$ improvement in voltage control efficiency and a $1 \%$ reduction in micro grid electrical power losses.

\section{REFERENCES}

[1] S. Angadi, U. R. Yaragatti, Y. Suresh and A. B. Raju, "Comprehensive review on solar, wind and hybrid wind-PV water pumping systems-an electrical engineering perspective," CPSS Transactions on Power Electronics and Applications 6(1): 1-19, 2021.

[2] B. Singh, R. Sharma and S. Kewat, "Robust Control Strategies for SyRG-PV and Wind-Based Islanded Microgrid," IEEE Transactions on Industrial Electronics 68(4): 3137-3147, 2021.

[3] S. Kewat and B. Singh, "Robust Control for Islanded and Seamless Mode Switching of Wind-PV Grid-Tied Generation System," IEEE Transactions on Industry Applications 57(5): 5285-5295, 2021.

[4] N. M. Dehkordi, N. Sadati and M. A. Hamzeh "Back stepping highorder sliding mode voltage control strategy for an islanded microgrid with harmonic/interharmonic loads" Control Engineering Practice 58: 150-160, 2017.

[5] Y. Li, D. M. Vilathgamuwa and P. C. Loh "Microgrid power quality enhancement using a three-phase four-wire grid-interfacing compensator" IEEE Transactions on Industry Applications 41(6): 1707-1719, 2005.

[6] K. Prabaakaran, N. Chitra and A. S. Kumar "Power quality enhancement in microgrid-A survey" ICCPCT, International Conference on Circuits, Power and Computing Technologies 126-131, 2013.

[7] M. Mehrasa, E. Pouresmaeil, H. Mehrjerdi, B.N. Jørgensen and J. P. Catalão "Control technique for enhancing the stable operation of distributed generation units within a microgrid" Energy Conversion and Management 97, 362-373, 2015.

[8] I. Y. Chung, W. Liu, D. A. Cartes, E. G. Collins and S. I. Moon, "Control methods of inverter-interfaced distributed generators in a microgrid system," IEEE Transactions on Industry Applications 46(3): 1078-1088, 2010.

[9] Y. Li and Y. W. Li, "Power management of inverter interfaced autonomous microgrid based on virtual frequency-voltage frame" IEEE Transactions on Smart Grid 2(1): 30-40, 2011.

[10] M. Dubarry, A. Devie and K. McKenzie, "Durability and reliability of electric vehicle batteries under electric utility grid operations: Bidirectional charging impact analysis" Journal of Power Sources 358, 3949, 2017.

[11] Y. Shi, R. Li, Y. Xue and H. Li, “High-frequency-link-based grid-tied PV system with small DC-link capacitor and low-frequency ripple-free maximum power point tracking,' IEEE Trans. Power Electron 31(1): 328-339, 2016.

[12] K. S. H. Beagam, R. Jayashree and M. A. Khan, “A new DC power ow model for $Q$ ow analysis for use in reactive power market,"
International Journal of Engineering Science and Technology 20(2): 721-729, 2017.

[13] H. Liu and J. Sun, "Voltage stability and control of offshore wind farms with AC collection and HVDC transmission,' IEEE Journal of Emerging and Selected Topics in Power Electronics 2(4): 1181-1189, 2014.

[14] A. Mohantya, M. Viswavandyaa, S. Mohantyb, P. K. Rayc and S. Patrad, "A new DC power ow model for Q ow analysis for use in reactive power market,' International Journal of Electrical Power \& Energy Systems 20, 444- 458, 2016.

[15] S. Kazemlou and S. Mehraeen, "Decentralized discrete-time adaptive neural network control of interconnected DC distribution system,', IEEE Transactions and Smart Grid 5(5): 2496-2507, 2014.

[16] M. Nijhuis, M. Gibescu, and J. F. G. Cobben, "Application of resilience enhancing smart grid technologies to obtain differentiated reliability," IEEE 16th International Conference on Environment and Electrical Engineering (EEEIC), Florence, Italy: 1-6, 2016.

[17] E. JimØnez, M. J. Carrizosa, A. Benchaib, G. Damm and F. Lamnabhi-Lagarrigue, "A new generalized power flow method for multi connected DC grids,', International. Journal of Electrical Power and Energy Systems 74, 329- 337, 2016.

[18] B. P.DeCampos, L. A. R. De Sousa and P. F. Ribeiro, "Mitigation of harmonic distortion with passive filters," IEEE 17th International Conference on Harmonics and Quality of Power, (ICHQP '16): 646651, Brazil, October 2016.

[19] K. H. Shafad, J. J. Jamian and S. A. S. Nasir, "Harmonic distortion mitigation for multiple modes charging station via optimum passive filter design," IEEE Conference on Systems, Process and Control, (ICSPC '16): 219-223, Malaysia, December 2016.

[20] V.-L. Nguyen, T. Tran-Quoc and S. Bacha, "Harmonic distortion mitigation for electric vehicle fast charging systems," IEEE Grenoble Conference Power Tech, (POWERTECH '13): 1-6, Grenoble, France, June 2013.

[21] C. C. Hao, Y. J. Tang and J. Shi, "Study on the harmonic impact of large scale electric vehicles to grid," AMM Applied Mechanics and Materials 443, 273-278, 2013.

[22] S. Pirouzi, M. A. Latify, and G. R. Yousefi, "Investigation on reactive power support capability of PEVS in distribution network operation," IEEE 23rd Iranian Conference on Electrical Engineering, (ICEE '15): 1591-1596, Tehran, Iran, May 2015.

[23] Y.Cho and H.Cha, "Single-tuned passive harmonic filter design considering variances of tuning and quality factor," Journal of International Council on Electrical Engineering, 1: 7-13, 2011.

[24] S. Sakar, M. E. Balci, S. H. E. Abdel Aleem, and A. F. Zobaa, "Increasing PV hosting capacity in distorted distribution systems using passive harmonic filtering," Electric Power Systems Research 148, 74$86,2017$.

[25] S. Farkoush, C. Kim, and S. Rhee, "THD reduction of distribution system based on ASRFC and HVC method for SVC under EV charger condition for power factor improvement," Symmetry 8(12): 156, 2016.

[26] N. Kasa, T. Iida and H. Iwamoto, "An inverter using buck-boost type chopper circuits for popular small-scale photovoltaic power system" IEEE 1, 185-902018.

[27] P. Zhang, W. Li, S. Li, Y. Wang and W. Xia, "Reliability assessment of photovoltaic power systems: Review of current status and future perspectives" Applied Energy 104, 822-33, 2013.

[28] M. Nagao, H. Horikawa and K. Harada, "Photovoltaic system using buck- boost PWM power inverter" Electrical Engineering in Japan 115(5): 128-39, 2016.

[29] A. Kumar Shrivastav, P. Kumar Sadhu and A. Ganguly, "Performance Analysis of Transient Current Limiter in Distribution System" Engineering, Technology \& Applied Science Research 8(2): 26402645, 2018.

[30] S. Jain and V. Agarwal, "A Single-Stage Grid Connected Inverter Topology for Solar PV Systems with Maximum Power Point Tracking” IEEE Transactions on Power Electronics 22: 5, 2017.

[31] Y. Xue, M. Manjrekar, M. Chenxi, C. Lin, M. Tamayo and J. N. Jiang, "Voltage Stability and Sensitivity Analysis of Grid-Connected" Photovoltaic Systems IEEE Conference 2011.

[32] A. K. Shrivastav, P. Kumar Sadhu and A. Ganguly, "Stability and Harmonic Analysis of A Transient Current Limiter in Distribution System" Microsystems Technologies, Springer-Verlag GmbH Germany, part of Springer Nature: 0946-7076, 2018. 


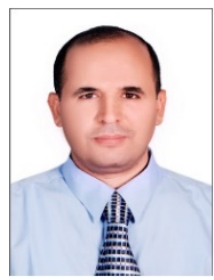

Dr. Adel Elgammal is currently an Associate Professor at the University of Trinidad and Tobago UTT, Department of Energy Systems. He received his B.Sc. Degree in Electrical Power Engineering from Helwan University-EGYPT in 1996. He completed his M.Sc. Degree in Electric Drives and Machines Engineering in 2002 and Ph.D. Degree in Jan-2007 from the Faculty of Engineering (Helwan University-EGYPT). In May 2008, Dr. Elgammal joined the University of Trinidad and Tobago (UTT) as an Assistant Professor and then he was promoted to Associate Professor in May 2010 at the Energy Department, UTT. Dr. Elgammal authored and co-authored over 47 Scholarly Technical Journals, and over 77 Refereed Conference Publications and three Engineering Book Chapters. In 2010, Dr. Elgammal has been elevated to senior member of Institute of Electrical and Electronics Engineers (IEEE), the world's largest professional association dedicated to advancing technological innovation and excellence for the benefit of humanity. His current Research areas include Power Systems and Electro-Technology, Motor Drives, FACTS Technology, Renewable/Alternate Energy Systems, Harmonics and Power Quality, Application of Intelligent Systems (Particle Swarm Optimization PSO, Fuzzy Logic, Neutral Networks, and Genetic Algorithms) to Power Systems, Renewable / Green Energy Systems and Electric Drives, Application of Power Electronics to Power Systems, Computer-Based Controllers. Dr. Elgammal has gained industrial and academic experience as well as participated in several technical consultations and professional experience.

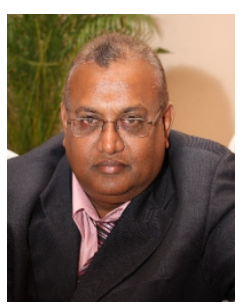

Dr. Tagore Ramlal is currently an Assistant Professor in Utilities Engineering, University of Trinidad and Tobago. He has been involved in the field of training and development in Electrical Engineering with diversified experience of thirty- six years (36) at the tertiary level. His contribution towards professional outreach program spans twentythree (23) years with expertise in consultation, development and facilitation of specialized industry courses. He also has extensive experience (16) years in electrical engineering design and consultancy services. Tagore has been employed with University of Trinidad and Tobago since 2000. 